\title{
REVIEW
}

\section{Myocardial hibernation and stunning: from physiological principles to clinical practice}

\author{
S R Redwood, R Ferrari, M S Marber
}

In patients with coronary artery disease, one of the most powerful determinants of prognosis is left ventricular function. ${ }^{12}$ Thus, if we assume that the prognostic benefit of revascularisation is mediated through an effect on left ventricular function, two mechanisms might explain this benefit. First, coronary artery bypass surgery or angioplasty could reduce the impact of coronary artery disease on the attrition of left ventricular function-in other words, left ventricular function deteriorates more slowly following revascularisation. Second, revascularisation could improve left ventricular function per se; this mechanism assumes that there must be areas of the heart that are alive but not contracting properly, and that revascularisation will improve this contractile dysfunction. Thus impairment of left ventricular function does not necessarily mean that the myocardium is dead, but rather that it may be alive though with reduced function. This has stimulated much research into the mechanisms of reversible left ventricular dysfunction and how best to identify it.

Traditionally, presurgical investigation of patients with ischaemic heart disease has involved an exercise test and coronary angiography, and so concentrates on the first mechanism while largely ignoring the concept of reversible left ventricular dysfunction, despite its documented potential importance. ${ }^{3}$ In unselected patients with left ventricular dysfunction (ejection fraction less than $30 \%$ ) undergoing surgical revascularisation, ejection fraction at six months can improve by up to $50 \% .^{3}$ In patients with an ejection fraction of less than $40 \%$, the presence of a mismatch between perfusion and viability predicted improvement in heart failure after revascularisation; furthermore, in patients treated medically, the presence of mismatch was associated with worse survival than in those without mismatch but with a similar initial ejection fraction. ${ }^{4}$

Thus the identification of these patients may be of clinical importance and, if so, requires some understanding of the physiological processes underlying reversible left ventricular dysfunction. The aims of this paper are to outline some of the physiological principles and controversies underlying reversible contractile dysfunction and to highlight current knowledge on how best to identify patients who might derive the most benefit from revascularisation.

\section{Causes of reversible left ventricular dysfunction}

From experimental studies, two main processes have been described, distinguished on the basis of resting myocardial blood flow. The concept of myocardial "hibernation" was introduced nearly two decades ago ${ }^{5}$ to describe impaired left ventricular function that improves following revascularisation. The original definition did not specify whether there was an abnormality in resting myocardial blood flow; however, it became widely accepted that hibernation was the result of reduced resting myocardial blood flow. ${ }^{56}$ Another form of

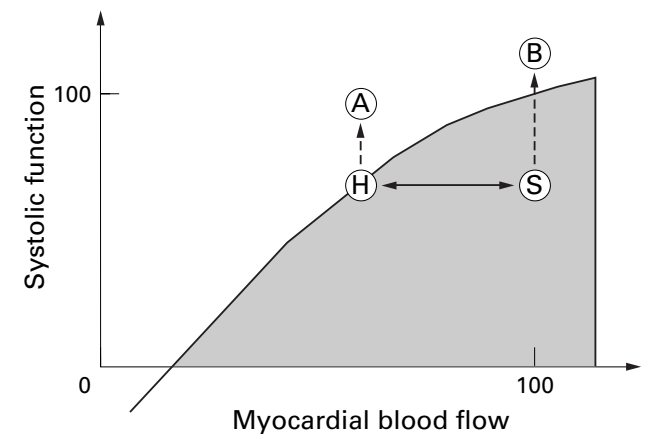

Figure 1 The relation between myocardial blood flow and systolic function, the "flow-function" relation, which was derived from short term experiments. When flow is reduced for longer periods (weeks to months), it is likely that this relation becomes much steeper..$^{10}$ When myocardium is operating below this line, function is disproportionately depressed relative to flow- that is, the myocardium is stunned ( $\mathrm{S}$ on the diagram). When myocardium is operating above this line function exceeds flow, and ischaemia is likely to result. Chronically hypoperfused myocardium, as a result of an epicardial stenosis restricting basal coronary flow, will be operating on the line $\mathrm{H}$ in the diagram). Conversely, the situation $\mathrm{S}$ is the result of repetitive bouts of demand ischaemia in a segment of myocardium subtended by a stenosis that severely limits flow reserve, but not basal coronary flow. Myocardial blood flow is likely to vary owing to small alterations in transmyocardial vascular resistance, as a result of changes within the stenosis and/or microvasculature (see text). Since the chronic relation between perfusion and contraction is likely to be steeper than depicted, these small variations in flow may result in an interchange of $\mathrm{H}$ and $\mathrm{S}$, without any appreciable change in systolic function. Following, inotropic stimulation, it is unlikely that myocardial blood flow will increase substantially. Thus myocardium operating at $\mathrm{H}$ will increase systolic function to point $\mathrm{A}$, which will exceed that expected from blood flow, and it is likely that thi increase in function will be curtailed by the onset of ischaemia. In stunned myocardium (S), function could increase to point B before function exceeds that expected from blood flow. Thus in both circumstances there can be a bimodal response to inotropes, and therefore the two cannot be reliably distinguished by stress echocardiography.
Accepted for publication 13 May 1998 


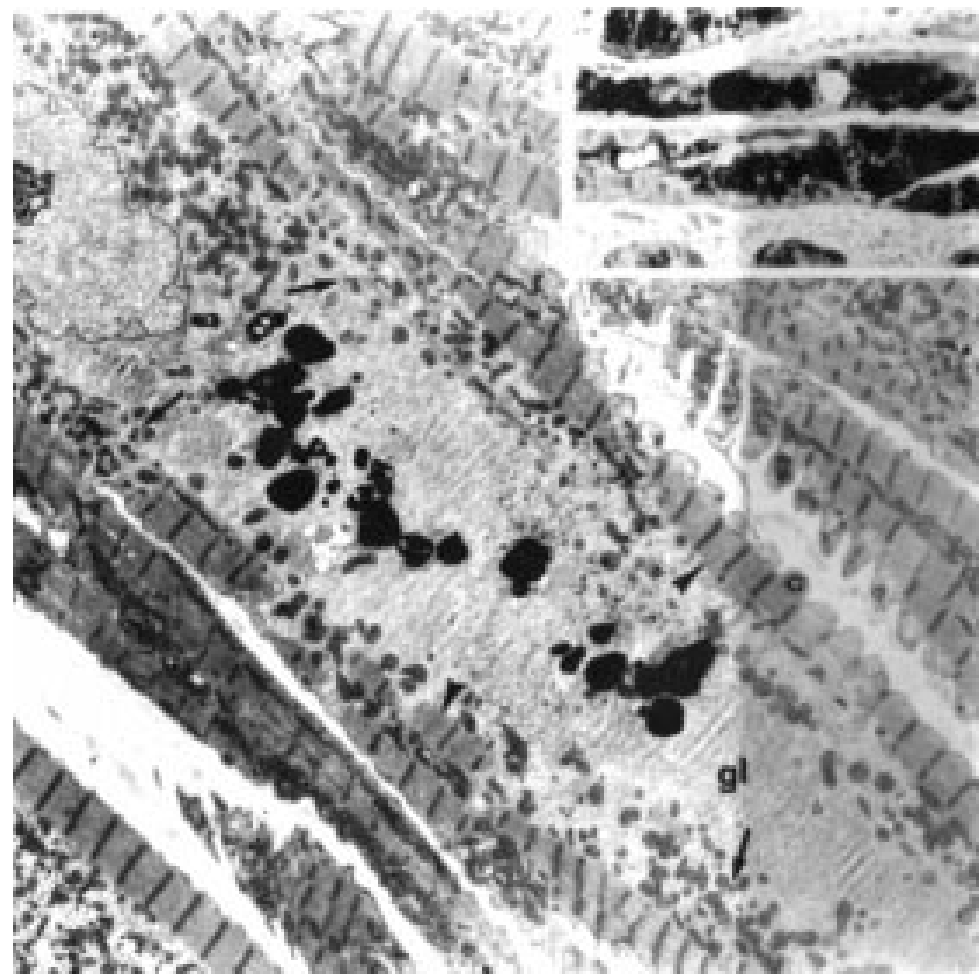

Figure 2 The electron microscopy appearance of a myocyte in a region of reversible left ventricular dysfunction, taken from a patient undergoing operative revascularisation. Sarcomeres, which normally occupy the myocyte, are confined to the subsarcolemmal margins (arrowhead). In addition, mitochondria are virtually absent and those that are present are small and round (arrows). Furthermore, there is marked glycogen accumulation (gl). [Photomicrograph supplied by Prof M Borgers, Department of Morphology, Fanssen Research Foundation, Beerse, Belgium.]

reversible segmental myocardial dysfunction, "stunning," was also described where resting myocardial perfusion was normal. Heyndrickx et al observed from canine experiments that "the myocardium rendered ischaemic, but not irreversibly damaged, exhibits prolonged depression of regional myocardial function, long after the complete return of blood flow and resumption of a normal electrocardiographic pattern."7

One of the crucial differences between these two experimental concepts is that resting myocardial perfusion is normal or near normal in stunning, but is reduced in hibernation. In order to differentiate between these phenomena in humans, one must therefore have a measure of myocardial blood flow.

\section{The physiology of perfusion-contraction matching}

The relation between myocardial blood flow and systolic function-the so called "flowfunction" relation ${ }^{8}$ - is shown in fig 1 . As blood flow is reduced, there is a corresponding reduction in contractile performance ("perfusion-contraction matching"). Provided this occurs slowly, ischaemia should not occur.

If blood flow remains low, the myocardium may be able to reduce its metabolic requirements still further by undergoing a more chronic form of adaptation involving alterations in the morphology and protein content of the myocardium (fig 2). ${ }^{11-15}$ These changes, which have been well documented and can be quite profound, are viewed by some as an adaptation to substrate deprivation, and by others as degeneration. ${ }^{12-14} 16$ This view of dedifferentiation or embryonic regression is that of an active adaptive process to altered flow, the so called "smart heart" hypothesis. The alternative is that this is not adaptation, but forced degeneration. Supporting this is the observation that some myocytes show nucleolar condensations suggestive of apoptosis. ${ }^{17}$ In addition, it is consistent with experimental data showing that cardiac myocyte apoptosis can be triggered by ischaemia. Whatever the cause, structural remodelling would be necessary to restore contractility and thus chronically impaired but viable myocardium may take weeks or months to recover once flow is restored. ${ }^{8}$

\section{The physiology of stunning}

Figure 3 shows the effect of brief coronary occlusion on systolic function in the dog. ${ }^{18}$ Immediately after occlusion, contractility falls and the myocardium becomes dyskinetic. When flow is restored, function can take days to recover fully. Thus following restoration of flow there is a mismatch between perfusion and contraction ("stunning") until full recovery of function.

A prerequisite for perfusion-contraction matching and stunning is that there must be an abnormality of myocardial blood flow. From

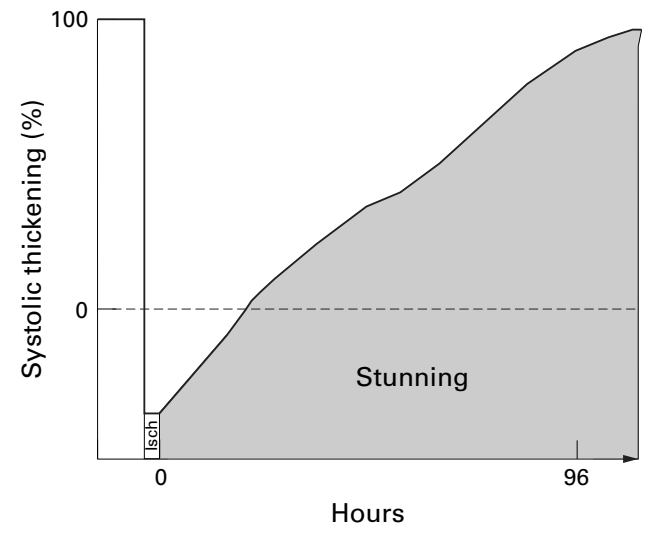

Figure 3 The effect of brief coronary occlusion on systolic function in the dog. The dark shaded box indicates a short episode of ischaemia. The myocardium rapidly becomes dyskinetic and following restoration of flow there is a gradual return of function. This period between the episode of ischaemia and recovery of full function is known as stunning. (Adapted from Bolli et al. ${ }^{18}$ )

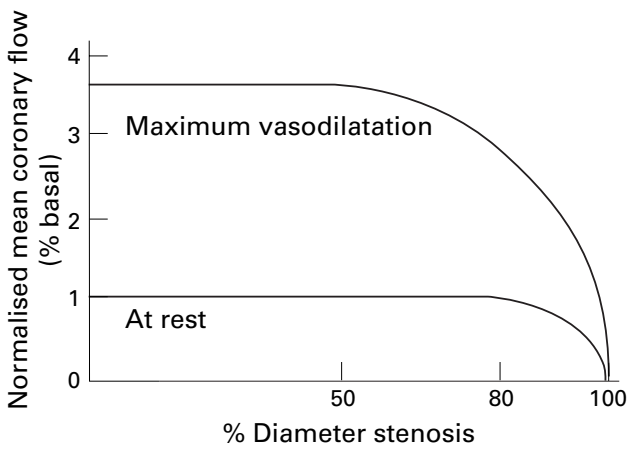

Figure 4 The relation between resting and maximum myocardial blood flow at different degrees of stenosis severity. See text for details. (Adapted from Gould et al. ${ }^{19}$ ) 


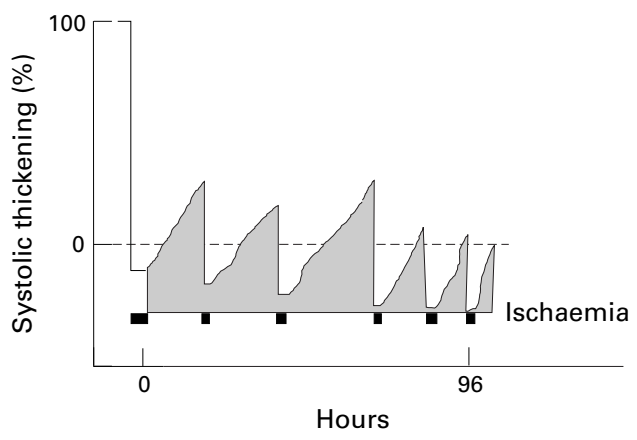

Figure 5 Repetitive stunning. The black boxes indicate short episodes of ischaemia. Contractility starts at 100\% and rapidly falls during the first episode of ischaemia. Following restoration of flow, contractility starts to improve, but before it has returned to normal, a further episode of ischaemia ensues, resulting in a further reduction in contractility. Repeated short episodes of ischaemia may therefore result in an apparent chronic impairment of contractility (see text). (Adapted from Bolli. ${ }^{25}$ )

experimental studies, fig 4 shows the relation between resting and maximal myocardial blood flow at different degrees of stenosis severity, ${ }^{1920}$ and this relation has also been investigated in humans using positron emission tomography. ${ }^{21}$ If contributions from collaterals, plaque morphology, and abnormal microvasculature are ignored, then a coronary stenosis of up to approximately $40 \%$ will not alter maximum blood flow, and thus coronary flow reserve will remain normal. Between $40 \%$ and $80 \%$, there will be normal resting myocardial blood flow, but maximum blood flow will be diminished, and following episodes of increased oxygen demand this may result in stunning. A stenosis greater than $80 \%$ is likely to be associated with a reduction in resting blood flow and could result in reduced contraction through perfusion-contraction matching. The difference between hibernation and stunning is therefore likely to be only one of degree: in hibernation resting blood flow is low, whereas in stunning resting flow is normal but maximal blood flow is reduced.

Although not demonstrated in all studies, in ambulant patients with coronary artery disease, transient disturbances of contraction have been documented following exercise, ${ }^{22-24}$ particularly in patients with multivessel disease. ${ }^{22}{ }^{24}$ It seems likely that transient wall motion abnormalities will occur in areas of myocardium subtended by a coronary stenosis that is not severe enough to diminish resting myocardial blood flow, but will impair coronary flow reserve. Thus the myocardium may become ischaemic following exercise, and before it has had time to recover fully another period of ischaemia may occur (fig 5). Repeated episodes of ischaemia may therefore result in an apparent chronic reduction in left ventricular function. ${ }^{26}$

Evidence from patients suggests that absolute myocardial blood flow may be normal or near normal in hibernating segments. ${ }^{27}{ }^{28}$ However, coronary flow reserve (that is, the ratio of maximum to basal coronary flow) has been shown to be reduced within the affected segments, ${ }^{28}$ leading to the hypothesis that hibernation is actually a result of repetitive stunning, secondary to repetitive episodes of ischaemia.

Coincident with the exploration of stunning and hibernation was the discovery of ischaemic preconditioning. This was originally defined as a brief period of ischaemia protecting the myocardium from a subsequent more prolonged period of ischaemia. ${ }^{29}$ Implicit in this definition, and the original experiments, was a defined period of reperfusion between the triggering (preconditioning) ischaemia and the subsequent prolonged period of ischaemia. However, in later experiments this was not found to be a necessity; the phenomenon also being triggered if the onset of the lethal ischaemia was gradual (sublethal) rather than sudden, so called intraischaemic preconditioning. ${ }^{30}$ What is immediately apparent is that classic preconditioning resembles repetitive stunning, while flow-function matching resembles intraischaemic preconditioning. It is thus possible that one of the mechanisms by which clinically hibernating myocardium survives the disturbance in myocardial blood flow is by being preconditioned.

In humans, there are extensive autoregulatory processes that maintain coronary blood flow despite changes in mean coronary pressure (fig 6). ${ }^{31}$ Over a wide range of coronary pressures, coronary blood flow remains normal, largely through variations in coronary tone. As coronary pressure falls, vasodilatation occurs, maintaining flow. Once maximum

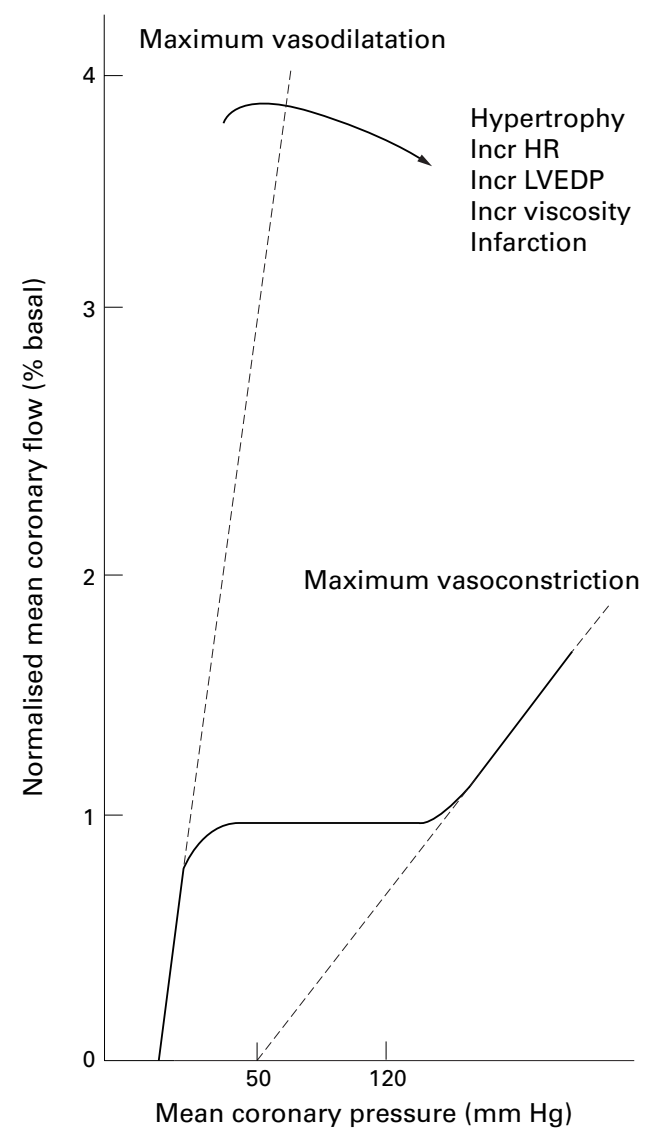

Figure 6 Relation between coronary blood flow and coronary pressure. Adapted from Hoffman. ${ }^{31}$ See text for explanation. 
vasodilatation is present, any further reduction in coronary pressure will result in a precipitous fall in flow. Conversely, as coronary pressure is increased, progressive vasoconstriction occurs until a point when further increases in pressure result in an increase in flow. This description is certainly an oversimplification, and the relation between pressure and flow is influenced by numerous factors-for example, hypertrophy, tachycardia, left ventricular end diastolic pressure, viscosity, infarction, medial smooth muscle tone, and cyclical platelet aggregationwhich would all tend to alter the gradient of this relation.

Thus it is conceivable that in the presence of a high grade stenosis, flow which was normal at rest may at times be reduced, and vice versa. If this is viewed in terms of perfusion-contraction matching, then it is clear that myocardium which at one time point is by definition "stunned" may at another time point be hypoperfused and therefore "hibernating" without there ever being any alteration in the amplitude of contraction (see legend to fig 1). In addition to this variability is the alteration as a result of transmural variations in myocardial blood flow. Thus within one hypocontractile segment it is possible that areas of dysfunction secondary to stunning and hypoperfusion may coexist at one point in time and then interchange at another.

So the differentiation between stunning and clinical hibernation is blurred and does not appear to be crucial. In both, there is a resting wall motion abnormality occurring as a result of coronary disease, which improves following revascularisation. In addition, both will respond to inotropes (at least initially-see below). Also, in both there is a switch from free fatty acids to glucose as the preferred substrate, and there is an intact trans-sarcolemmal potassium gradient. These metabolic and physiological properties are used in the assessment of reversibly dysfunctional, viable myocardium.

\section{Identification of viable myocardium}

In patients with impaired left ventricular function, it is important to differentiate infarction from viability, because in viable myocardium, impaired function is potentially reversible. As already discussed, the differentiation of hibernation from stunning is difficult and probably of little clinical relevance, and it is likely that the two processes coexist within different areas of myocardium with impaired systolic function. There are three relatively non-invasive imaging techniques that have been shown to be useful for predicting whether an abnormality in wall motion will improve after revascularisation: dobutamine echocardiography, thallium with rest redistribution or reinjection, and positron emission tomography (PET).

In viable but non-contracting segments of myocardium that are either hypoperfused or have normal resting blood flow, there may be an inotrope reserve which is thought to be reduced by the onset of ischaemia, and this concept is used in dobutamine echocardiography. ${ }^{32-35}$ In stunned areas with normal resting flow, contraction may initially increase, only to be diminished by the onset of ischaemia as coronary flow reserve is exhausted, resulting in a bimodal contractile response to dobutamine (see fig 1). In areas of resting hypoperfusion there is no flow reserve and any increase in contractility will almost immediately cause ischaemia. ${ }^{32}$ Thus, in response to dobutamine, hypokinetic segments that become more hypokinetic, with or without a noticeable early augmentation of contraction, are likely to improve after revascularisation.

Thallium $\left({ }^{201} \mathrm{Tl}\right)$ is a gamma emitter that is avidly taken up by viable cells since it has a volume of distribution similar to that of potassium, and it is used as a tracer to identify viable myocardium..$^{33} 36$ Uptake into cells is rapid, and so the early pattern of distribution is proportional to blood flow, while the late pattern of distribution indicates tissue with an intact intracellular to extracellular potassium gradient. Thus the combination of early and delayed imaging will differentiate viable from infarcted tissue.

Positron emission tomography (PET) uses [18F]fluorodeoxyglucose (FDG), a positron emitter which is taken up by metabolically active tissue, and therefore images myocardium in a manner analogous to ${ }^{201} \mathrm{Tl}{ }^{38}{ }^{39}$ Although it is debatable whether FDG is handled in an identical manner to glucose, it does seem to be preferentially concentrated in hibernating myocardium, ${ }^{15}$ perhaps because of the rich glycogen content of this tissue. Whatever the mechanism of uptake, it cannot differentiate stunned from hibernating myocardium. With the simultaneous use of $[13 \mathrm{~N}]$ ammonia, ${ }^{28}{ }^{38-42}$ or perhaps better $[15 \mathrm{O}] \mathrm{H}_{2} \mathrm{O},{ }^{27}{ }^{42-44}$ it is possible to quantitative absolute regional myocardial blood flow and thus differentiate stunning from hypoperfusion. However, this technique is not currently in widespread clinical use.

There is some evidence to suggest that not all hypokinetic areas predicted to improve on the basis of imaging do in fact improve after revascularisation. ${ }^{45}$ Thus some patients may be exposed to the risks of revascularisation without immediate or even late benefit. This lack of contractile recovery has been associated with extensive histological changes in the extracellular matrix. ${ }^{10}{ }^{46}$ However, at present it seems that all the imaging modes have broadly similar sensitivity and specificity for predicting eventual contractile recovery.

It may be important to be able to distinguish hibernating segments that will recover slowly from those that will recover more rapidly after revascularisation. This is useful as it would give an indication of left ventricular function in the early postoperative period, and thus an indication of early postoperative morbidity and mortality. Although no formal comparisons of the time course of contractile recovery between different imaging modes has been made, it is likely that myocardium which has a demonstrable inotrope reserve will recover very early postoperatively. ${ }^{47}$ Thus dobutamine echocardiography may be most useful in patients with severely impaired left ventricular function, where the main concern is of operative or in-hospital mortality; whereas thallium scanning 
Table 1 Differentiation between hibernation and stunning

\begin{tabular}{|c|c|c|}
\hline & Hibernation & Stunning \\
\hline Response to inotropes & $\uparrow$ then $\downarrow \downarrow$ & $\uparrow$ then ? $\downarrow$ \\
\hline Glycolysis & $\uparrow \uparrow$ & $\uparrow$ \\
\hline Blood flow at rest & Slight $\downarrow$ & Normal \\
\hline Coronary flow reserve & $\downarrow \downarrow$ & \\
\hline$\left[\mathrm{K}_{\mathrm{i}}\right] /\left[\mathrm{K}_{0}\right]$ & Normal & Normal \\
\hline Recovery following revascularisation & $\uparrow \uparrow$ & $\uparrow \uparrow$ \\
\hline
\end{tabular}

or PET may be most useful for patients with moderate left ventricular impairment, where the concern is not so much of in-hospital mortality, but of eventual functional improvement.

\section{Conclusion}

"Hibernation" in the clinical context may be the result of repetitive stunning or low resting myocardial blood flow causing chronic perfusioncontraction matching. Recent evidence appears to favour the former. However, it is neither necessary, nor practical, to differentiate these two physiological conditions (table 1). It would be more important to be able to detect fibrosis non-invasively, and to be able to predict the rate and eventual degree of contractile recovery following revascularisation.

1 Multicenter Post Infarction Research Group. Risk stratification and survival after myocardial infarction. $N$ Engl f Med 1983;309:331-6.

2 Bigger JT, Fleiss J, Kleiger R, et al., and Multicenter Post Infarction Research Group. The relationships among Infarction Research Group. The relationships among ventricular arrhythmias, left ventricular dysfunction and mortality in the 2 years $1984 ; 69: 250-8$.

3 Elefteriades JA, Tolis G, Levi E, et al. Coronary artery bypass grafting in severe left ventricular dysfunction: excellent survival with improved ejection fraction and functiona state. F Am Coll Cardiol 1993;22:1411-17.

4 Di Carli MF, Davidson M, Little R, et al. Value of metabolic imaging with positron emission tomography for evaluating prognosis in patients with coronary artery disease and left ventricular dysfunction. Am $\mathcal{F}$ Cardiol 1994;73:527-33.

5 Diamond GA, Forrester JS, deLuz PL, et al. Postextrasystolic potentiation of ischemic myocardium by atrial stimulation. Am Heart f 1978;95:204-9.

6 Rahimtoola SH. The hibernating myocardium. Am Heart $f$ 1989;117:211-21.

7 Heyndrickx GR, Millard RW, McRitchie RJ, et al. Regional myocardial functional and electrophysiological alterations after brief coronary artery occlusion in conscious dogs. $\mathcal{F}$ after brief coronary artery
Clin Invest $1975 ; 56: 978-85$.

8 Ross J. Myocardial perfusion-contraction matching. Circulation 1991;83:1076-83.

9 Gallagher KP. Myocardial hibernation in terms of the flowfunction relationship. Basic Res Cardiol 1995;90:12-15.

10 Vanoverschelde J-LJ, Wijns W, Borgers M, et al. Chronic hibernation in humans. From bench to bedside. Circulation 1997;95:1961-71.

11 Vanoverschelde JL, Wijns W, Depre C, et al. Mechanisms of chronic regional postischemic dysfunction in humans. New insights from the study of noninfarcted collateraldependent myocardium. Circulation 1993;87:1513-23.

12 Ausma J, Cleutjens J, Thone F, et al. Chronic hibernating myocardium: interstitial changes. Mol Cell Biochem 1995; 147:35-42.

13 Ausma J, Furst D, Thone F, et al. Molecular changes of titin in left ventricular dysfunction as a result of chronic hibernation. $\mathcal{F ~ M o l ~ C e l l ~ C a r d i o l ~ 1 9 9 5 ; 2 7 : 1 2 0 3 - 1 2 . ~}$

14 Borgers M, Thone F, Wouters L, et al. Structural correlates of regional myocardial dysfunction in patients with critical coronary artery stenosis: chronic hibernation? Cardiovasc Coronary artery steno
Pathol 1993;2:237-45.

15 Depre C, Vanoverschelde J-LJ, Melin JA, et al. Structural and metabolic correlates of the reversibility of chronic lef ventricular ischemic dysfunction in humans. Am F Physiol 1995;268:H1265-75.

16 Ausma J, Schaart G, Thone F, et al. Chronic ischemic viable myocardium in man: aspects of dedifferentiation. Cardiovasc Pathol 1995;4:29-37.

17 Schwarz ER, Schaper J, Vom Dahl J, et al. Myocyte degeneration and cell death in hibernating human myocardium. 7 Am Coll Cardiol 1996;27:1577-85.

18 Bolli R, Zhu WX, Thornby JI, et al. Time course and determinants of recovery of function after reversible ischemia in conscious dogs. Am 7 Physiol 1988;254:H102-14.

19 Gould KL, Lipscomb K, Hamilton GW. Physiologic basis for assessing critical coronary stenosis. Instantaneous flow
response and regional distribution during coronary hyperemia as measures of coronary flow reserve. Am $\mathcal{f}$ Cardiol 1974;33:87-94.
20 Gould KL, Lipscomb K. Effects of coronary stenoses on coronary flow reserve and resistance. Am $\mathcal{F}$ Cardiol 1974;34:48-55.

21 Uren NG, Melin JA, De Bruyne B, et al. Relation between myocardial blood flow and the severity of coronary artery stenosis. N Engl f Med 1994;330:1782-8.

22 Robertson WS, Feigenbaum H, Armstrong WF, et al. Exercise echocardiography: a clinical practical addition in the evaluation of coronary artery disease. $7 \mathrm{Am}$ Coll Cardiol 1983;6:1085-9.

23 Scognamiglio R, Ponchia A, Fasoli G, et al. Exerciseinduced left ventricular dysfunction in coronary heart disease: a model for studying the stunned myocardium in man. Eur Heart F 1991;12:16-19.

24 Kloner RA, Allen J, Cox TA, et al. Stunned left ventricular myocardium after exercise treadmill testing in coronary artery disease. Am F Cardiol 1991;68:329-34.

25 Bolli R. Myocardial "stunning" in man. Circulation 1992;86: 1671-91.

26 Homans DC, Laxson DD, Sublett E, et al. Cumulative deterioration of myocardial function after repeated episodes of exercise-induced ischemia. Am $\mathcal{F}$ Physiol 1989;256: H1462-71.

27 Marinho NVS, Keogh BE, Costa DC, et al. Pathophysiology of chronic left ventricular dysfunction. Circulation 1996;93: 737-44.

28 Vanoverschelde J-LJ, Wijns W, Depre C, et al. Mechanisms of chronic regional postischemic dysfunction in humans. Circulation 1993;87:1513-23.

29 Murry CE, Jennings RB, Reimer KA. Preconditioning with ischemia: a delay of lethal cell injury in ischemic myocardium [abstract]. Circulation 1986;74:1124-36.

30 Ito BR. Gradual onset of myocardial ischemia results in reduced myocardial infarction. Association with reduced contractile function and metabolic downregulation. Circucontractile function and
lation $1995 ; 91: 2058-70$.

31 Hoffman JIE. Maximal coronary flow and the concept of coronary vascular reserve. Circulation 1984;70:153-9.

32 Afridi I, Kleiman NS, Raizner AE, et al. Dobutamine echocardiography in myocardial hibernation. Optimal dose and accuracy in predicting recovery of ventricular function after coronary angioplasty. Circulation 1995;91:663-70.

33 Perrone-Filardi P, Pace L, Prastaro M, et al. Assessment of myocardial viability in patients with chronic coronary artery disease. Circulation 1996;94:2712-19.

34 Sun KT, Czernin J, Krivokipich J, et al. Effects of dobutamine stimulation on myocardial blood flow, glucose metabolism, and wall motion in normal and dysfunctional myocardium. Circulation 1996;94:3146-54.

35 Cigarroa CG, deFilippi CR, Brickner ME, et al. Dobutamine stress echocardiography identifies hibernating myocardium and predicts recovery of left ventricular function after coronary revascularization. Circulation 1993;88: $430-6$.

36 Maddahi J, Garcia EV, Berman DS, et al. Improved non-invasive assessment of coronary artery disease by quantitative analysis of regional stress myocardial distribution and washout of thallium-201. Circulation 1981;64: 924-35.

37 Tamaki N, Yonekura Y, Senda M, et al. Value and limitation of stress thallium-201 single photon emission computed tomography: comparison with nitrogen-13 ammonia positron tomography. $7 \mathrm{Nucl}$ Med 1988;29:1181-8.

38 Marshall RC, Tillisch JH, Phelps ME, et al. Identification and differentiation of resting myocardial ischemia and infarction in man with positron computed tomography, ${ }^{18}$ F-labeled fluorodeoxyglucose and N-13 ammonia. Circulation 1983;67:766-78.

39 Yonekura Y, Tamaki N, Senda M, et al. Detection of coronary artery disease with ${ }^{13} \mathrm{~N}$-ammonia and high-resolution positron-emission computed tomography. Am Heart $f$ 1987;113:645-54.

40 Kuhle WG, Porenta G, Huang SC, et al. Quantification of regional myocardial blood flow using ${ }^{13} \mathrm{~N}$-ammonia and reoriented dynamic positron emission tomographic imaging. Circulation 1992;86:1004-17.

41 Bergmann SR, Hack S, Tewson T, et al. The dependence of accumulation of ${ }^{13} \mathrm{NH}_{3}$ by myocardium on metabolic factors and its implications for quantitative assessment of perfusion. Circulation 1980;61:34-43.

42 Nitzsche EU, Choi Y, Hoh CK, et al. Non-invasive quantification of myocardial blood flow in humans. A direct comparison of the $\left[{ }^{13} \mathrm{~N}\right]$ ammonia and the $\left[{ }^{15} \mathrm{O}\right]$ water techniques. Circulation 1996;93:2000-6.

43 Bergmann SR, Fox KA, Rand AL, et al. Quantification of regional myocardial blood flow in vivo with $\mathrm{H}_{2}{ }^{15} \mathrm{O}$. Circulation 1984;70:724-33.

44 Bergmann SR, Herrero P, Markham JS, et al. Non-invasive quantitation of myocardial blood flow in human subjects with oxygen-15-labeled water and positron emission tomography. F Am Coll Cardiol 1989;14:639-52.

45 de Silva R, Yamamoto Y, Rhodes CG, et al. Preoperative prediction of the outcome of coronary revascularization using positron emission tomography. Circulation 1992;86: 1738-42.

46 Marwick TH, MacIntyre WJ, Lafont A, et al. Metabolic responses of hibernating and infarcted myocardium to revascularization. Circulation 1992;85:1347-53.

47 La Canna G, Alfieri O, Giubbini R, et al. Echocardiography during infusion of dobutamine for identification of reversible dysfunction in patients with chronic coronary artery disease. $\mathcal{F}$ Am Coll Cardiol 1994;23:617-26. 